8

\title{
Food acceptance: The role of consumer perception and attitudes
}

\author{
E.Costell, A. Tárrega, S. Bayarri
}

Physical and Sensory Properties Laboratory. IATA.CSIC

PO Box 73. 461000 Burjassot. Valencia. SPAIN

\begin{abstract}
The process by which man accepts or rejects food is of a multi-dimensional nature. In complex food matrices, it is not always easy to establish relationships between the individual chemical stimuli concentration, physiological perception and consumer reaction. Consumers' responses to food are not only based on the sensory characteristics of the product and on their physiological status but they are also related to other factors, such as previous information acquired about the product, their past experience, and their attitudes and beliefs. This paper discusses different methods to obtain information about consumer perceptions, attitudes, beliefs and expectations.
\end{abstract}

Keywords: consumer response, perception, attitudes, expectations 
Introduction

25 Sensory quality should be considered as a key factor in food acceptance because consumers seek food with certain sensory characteristics. The acceptance of a food will depend on whether it responds to consumer needs and on the degree of satisfaction that it is able to provide (Heldman, 2004). The process by which man accepts or rejects food is of a multi-dimensional nature. Its structure is both dynamic and variable, not only among different individuals within a group but also within the same individual in different contexts and periods of time. Acceptance of a food is basically the result of the interaction between food and man at a certain moment (Shepherd, 1989). Food characteristics (chemical and nutritional composition, physical structure and properties), consumer characteristics (genetic, age group, gender, physiological and psychological state) and those of the consumer's environment (family and cultural habits, religion, education, fashion, price or convenience) the influence of consumers' decision to accept or reject a food (Shepherd, 1989; Shepherd and Sparks, 1994). Apart from the characteristics of the food itself and the sensations consumers experience when ingesting it, a consumer's purchase choice and even the degree of pleasure when consuming it can be influenced by their attitude and opinion about the nutritional characteristics (Bruhn et al., 1992), safety (Resurreccion and Galvez, 1999; Hashim et al., 1996, Wilcock et al. 2004) and even the trademark (Guerrero et al. 2000) or price (Caporale and Monteleone, 2001) of the product. Other aspects of consumer response to food must also be considered. For example, the relationships that exist between taste genetics, taste function markers and

47 preference or food intake (Dinehart et al, 2006) or the increase in acceptability due to habitual consumption (Luckow et al., 2005; Stein et al., 2003) or whether the 
49 food fulfils consumers' expectations of sensory quality (Cardello, 1994). All of

50 these influence consumer response and can lead to either repeated consumption

51 or rejection of a product

52 During food consumption, the brain receives different sensory inputs (visual,

53 olfactory, gustatory, tactile, trigeminal) and the information from physiologically

54 distinct sensory modes is integrated in the final sensory perception (Prescott,

55 2004, Small and Prescott, 2005). For consumers, each perceived sensation responds not only to a certain sensory input but also to the other inputs perceived simultaneously and to physical or perceptual interactions among them. Delwiche (2004) have reviewed how all these sensations interact, both at

59 the perceptual and the physical level, and discuss the impact that each one of

60 them has on flavour rating. Though all these inputs influence flavour perception,

61 through physical or perceptual interactions, the interaction between taste and odour is so strong that they jointly constitute the flavour perceived. When either the taste or the odour compound of a highly familiar odour-taste pair is 64 presented in isolation, it may elicit weak ratings of the missing component. For example, odours that are normally present together with sweet tastes in mouth, such as vanilla, are commonly described as "sweet" odours. This perception does not result from any direct physiological effect of such odours on taste receptor, but it reflects a central neural process which appears to be based

69 upon simultaneous associations between taste and smell. This type of learning

70 effect has also been observed for sour and bitter tastes, resulting in odours that smell "sour" and "bitter", respectively (Sundqvist et al, 2006). A distinctive characteristic of odour-taste integration is that for effect enhancement to occur, the odour and taste components must be perceptually congruent (White and 
74 Prescott, 2007). In studies using functional magnetic resonance imaging (fMRI), 75 de Araujo et al, (2003) and Rolls (2005) located where interactions between taste and odour stimuli take place in the human brain. Two taste stimuli and two odour stimuli were delivered unimodally or in different combinations. The results obtained revealed that while some brain areas respond to either taste or retronasal olfactory stimuli, other brain areas respond to both. De Araujo et al, 80 (2003) also showed that correlations with consonance ratings for smell and taste combinations and for their pleasantness were found in the medial anterior area of the orbitofrontal cortex. They concluded that these results provide evidence for the convergence of taste and olfactory stimuli to produce flavour and reveal where the pleasantness of flavour is perceived in the human brain. Moreover, flavour perception is highly dependent on both the subject's past experience with specific odour-taste combinations (the origin of congruence) and on the cognitive factors that determine whether the flavour elements are combined or not (Prescott, 2004).

90 In complex food matrices, it is not always easy to establish relationships between 91 the individual chemical stimuli concentration, physiological perception and consumer reaction. It is difficult to make predictions as to the possible perceptible 93 differences between products differing in composition and/or structure, as a result 94 of changes in formulation or processing. It is even more difficult to predict to what 95 degree the consumer will accept it and It is necessary to combine information on different factors: concentration of both volatile and non-volatile stimuli, structure 97 and other physical characteristics of the food matrix, physico-chemical 98 mechanisms governing the release of taste and odour compounds, product 
modification during oral food processing, sensory techniques to ascertain how

100 flavour is perceived and how this perception affects the final acceptance of the

101 product under study. Regarding this last point, one must bear in mind that when

102 consumers eat food their responses are not only based on the sensory

103 characteristics of the product and on their physiological status but they are also

104 related to other factors, such as previous information acquired about the product,

105 their past experience, and their attitudes and beliefs (Aaron et al., 1994; Cardello,

106 1994; Zandstra et al., 2001; Schifferstein, 2001; Barrios \& Costell, 2004; Wilcock

107 et al., 2004). The influence of attitudes, beliefs and opinions on food choice and

108 purchase is especially important in the acceptance or rejection of some types of

109 food such as organic food, genetically modified food or functional food, which are

110 presented to the consumer as a possible alternative to conventional food

111 (Roininen \& Tuorila, 1999, Connor \& Douglas, 2001; von Alvensleben, 2001;

112 Pearson, 2002). Consumer acceptance of organic, genetically modified or

113 functional food is far from being unconditional. Their benefits may provide added

114 value to consumers but cannot outweigh the sensory properties of foods (Siró et

115 al 2008).

117 In a simplified manner, consumer response to a given food is mainly defined by:

118 1) a sensory component, related with the sensory properties of the product; 2)

119 an affective component, responsible for positive or negative response towards a

120 product, 3) a cognitive component, coming from the knowledge and opinions

121 about a product; and 4) a behavioural component, involving intentions or

122 actions, defining how willing a consumer is to do something in certain situations.

123 The sensory component reflects an individual's sensory perception of the 
124 product; the affective component summarizes the general response a person

125 has to a product; the cognitive component is related to the information that a

126 person has about a product and to his/her attitudes and beliefs, while the

127 behavioural component is related to an action or intention and reflects the

128 person's intentions about his/her future behaviour.

129

130 In studies about food acceptability, four critical questions arise: how consumers

131 perceive the sensory characteristics of food; to what extent the variation in

132 perceived sensory characteristics influences consumer response; how certain

133 consumer habits, attitudes or beliefs affect hedonic ratings and purchase

134 intention and to what extent hedonic ratings are influenced by the expectations

135 created by different types of information.

\section{How consumers perceive sensory characteristics?}

138 Because knowing exactly what consumers perceive is difficult, the main goal of

139 studies about acceptability or preference is usually to establish the relationship

140 between the intensity of perceptible attributes and degree of acceptance

141 (Costell et al., 2000, Jaeger et al., 2003, Santa Cruz et al., 2002, Tenenhaus et

142 al., 2005, Rodbotten et al., 2009). Sensory evaluation of the perceptible

143 attributes of foods and beverages is usually carried out using conventional

144 techniques, such as descriptive analysis (Deliza et al. 2005). There are several

145 different methods of descriptive analysis, including the flavour profile method,

146 the $\mathrm{QDA}^{\circledR}$, the Spectrum ${ }^{\mathrm{TM}}$ method (Meilgaard et al. 1999) and the generic

147 descriptive analysis (Hersleth et al. 2005). However, most of these techniques

148 imply the use of trained and experienced assessors, who normally tend to 
149 generate complex and scientifically orientated terms. On the contrary, consumer

150 sensory panels generate easily understandable vocabularies, but have the

151 disadvantages that they are too personal to be interpreted by anyone except the

152 subject (Piggott et al., 1990). One way to avoid these drawbacks and to obtain

153 direct information about what sensations consumers perceive when eating food

154 is to use the Repertory Grid Method (RGM) in conjunction with the Free Choice

155 Profile (FCP) (Gómez et al., 1998, Jahan et al., 2005, Jaeger et al., 2005,

156 Hersleth et al., 2005). The RGM is the term used to describe a set of techniques

157 related to Kelly's personal construct theory which can be used to investigate the

158 individual constructs (Gains, 1994) and it seem particularly suited to develop

159 consumer-related vocabulary. A problem which usually arises when working

160 with consumers is to generate sufficient and suitable descriptors to describe

161 their sensory perceptions. As stated by Gains (1994), the idea behind the use of

162 RGM is that individuals should be able to create their own unique set of

163 constructs to describe a given set of objects. If there are common dimensions of

164 perception across consumers these will be manifest as geometrical similarities

165 in the mathematical spaces obtained for each individual data set. With respect

166 to FCP, on one hand, it differs from conventional profiling in that each consumer

167 develops an individual list of terms to describe the samples rather than using a

168 common scorecard. On the other hand, it is similar in that the assessors must

169 be able to detect differences between samples, verbally describe the perceived

170 attributes and quantify them (Oreskovich et al. 1991). The assessors only have

171 to be objective, capable of using line scales, and of using their developed

172 vocabulary consistently (Piggott et al., 1990). González-Tomas \& Costell (2006)

173 used the RGM plus FCP as a tool to obtain data on consumers' perceptions of 
174 the sensory characteristics of eight Spanish commercial vanilla dairy desserts.

175 The average sample space revealed that the consumers found the greatest

176 differences in color and texture of samples although differences in various flavor

177 notes were also perceived. The first dimension of sample space separated the

178 samples largely by yellow color intensity (pale yellow, soft yellow, deep yellow,

179 strong yellow, lemon yellow) and by consistency (liquid texture, light texture,

180 fluid texture, dense texture, thick texture, consistent texture). Dimension 2 was

181 mainly related to visual attributes of texture (light appearance, liquid

182 appearance, fluid appearance, liquid visual texture, thick visual texture), with

183 creaminess and with different flavor notes (vanilla, 'natillas' flavor, milk flavor,

184 off flavor). The third one was related to structural texture attributes (greasy,

185 compact, lumpy, earthy...), with yellow-orange color and with citric and artificial

186 flavors. The results obtained not only confirmed that the RGM in conjunction

187 with the FCP was a valuable tool to obtain data on consumers' perceptions but

188 also showed that consumers do not behave as a homogeneous group. Two

189 groups of consumers were detected: one of them separated samples mainly

190 according to yellow color intensity whereas the other related the largest

191 differences to textural characteristics. It can be concluded that the Repertory

192 Grid Method (RGM) in conjunction with the Free Choice Profile (FCP) constitute

193 a valid technique to obtain information about consumers' perceptions. One of

194 the advantages of FCP is that it allows one to gather information about cognitive

195 perception directly from consumers and to identify their common perceptual

196 dimensions (Gains \&Thompson 1990, Moskowitz, 1996, Russell \& Cox, 2003)

197 but it cannot be useful when used for describing sensory characteristics of

198 slightly different samples (Guerrero et al, 1997). As stated by Deliza et al 
199 (2005), FCP is a good method to obtain information on target consumers'

200 perceptions of a product, rather than the descriptive profile typically obtained by

201 a trained panel. Moreover, the data obtained from FCP cannot be analyzed

202 using traditional statistical methods due to the different dimension of individual

203 matrices. The individual configurations obtained can be matched and compared

204 by generalized Procrustes analysis and can be combined to form an average or

205 consensus configuration (Gower, 1975; Dijksterhuis \& Gower, 1991/2)

206

207 To what extent does the variation in perceived sensory characteristics

208 influence consumer response?

209 One must accept that variability in perceived intensity of certain attributes by a

210 trained panel or by a group of consumers may not affect acceptability. One way

211 to investigate this is to analyze the relationships between variations in attribute

212 intensity perceived by a trained panel and the variability in consumer

213 acceptability. This approach can tell us which attributes most influence

214 consumer acceptance. Validity of the results obtained with this approach mainly

215 depends on the homogeneity of the preference criteria of the consumers

216 surveyed. When the individual responses come from consumers with different

217 preference criteria, the average values obtained from the whole population

218 tested do not reflect the actual situation. Average results are not correctly

219 interpreted if the individual differences are ignored (Lundgren et al., 1978). To

220 study individual differences, the average values from the whole group of

221 consumers must be substituted by the analysis of the average values provided

222 by subgroups, created by classical segmentation criteria, like gender, age,

223 frequency of consumption, etc. (Thybo et al., 2004, Villegas et al., 2009a). 
224 Another possibility is to establish subgroups of consumers as a function of their

225 individual sensory preferences. Several techniques can be used to create the 226 subgroups: grouping those consumers who prefer the same products by

227 applying cluster analysis to the acceptance data (Vigneau et al., 2001; Santa

228 Cruz et al; 2002) or to study the structure of acceptability data with Internal

229 Preference Maps (Greenhoff \& MacFie, 1994). By analysing the relationships

230 between the dimensions of the preference map and the values assigned to the

231 intensity of the sensory attributes evaluated by a trained panel, information can

232 be obtained on the relative influence that each attribute has on each consumer

233 subgroup's acceptance criteria (Costell at al., 2000). Jaeger et al (2003) used

234 the Internal Preference Map to investigate consumers' preference criteria

235 regarding eight kiwi genotypes and concluded that the consumer population

236 studied responded differently to the different kiwi genotypes. Two of the

237 genotypes were particularly acceptable to one of the consumer subgroups but

238 not to another one. To identify consumer subgroups with different preference

239 criteria, Carbonell et al (2008) proposed a method based on the correlation

240 coefficients between consumer acceptability data and sensory-attribute intensity

241 scores from a trained panel. They correlated intensity data of the sensory

242 attributes of different apple varieties evaluated by a trained panel with

243 acceptability data from different consumer subgroups. Their results revealed

244 that one consumer subgroup preferred crispy, hard and acidic apples, whereas

245 the other subgroup preferred sweet and aromatic apples. These methods can

246 be used to identify groups of consumers with different preferences and can help

247 to explain why a consumer accepts some samples but rejects others according 
248 to the intensity of each sensory attribute. Nevertheless, this approach requires

249 the use of two types of panels: trained and consumers.

250

251 The approach is different when direct consumers' sensory evaluation is 252 important for product development, new-product development guidance or

253 product improvement and optimization. Consumer-orientated product 254 optimization involves the consumer in product development at an early stage 255 (Damasio et al., 1999; Gan et al., 2007, Choi et al 2007). In these situations one must remember there is not a direct connection between the independent factors (ingredients) controlled by the experimenter and the dependent factor (acceptability). It is necessary to analyze to what extent variation in ingredients or a possible interaction between them could cause perceptible variations in the sensory features and if any such variations affect acceptability. The Just About Right (JAR) scales can play a diagnostic role to determine how the consumer feels about the product. The data obtained with these scales provide an idea of the proportion of consumers who perceive each sample in a certain way and allow to determine how much the sample varied or to approach the intensity of an attribute considered ideal for a given product. As a rule of thumb, to conclude that a specific attribute is at its optimal level, a minimum of $70 \%$ of responses are usually expected to be in the "just about right" group, and to conclude that an attribute is not at its optimal level, usually a minimum of $20 \%$ of consumers necessarily falls in the "too weak" or "too strong" categories. The use of JAR scales for product optimization has been questioned by some

271 authors who do not consider it as effective as other methods (Epler et al, 1998).

272 Other authors indicate that JAR scales can be used with the hedonic scale in 273 consumer testing to provide directional information for food optimization (Gacula 
274 et al., 2008, Xiong \& Meullenet, 2006). Recently, Lovely \& Meullenet (2009)

275 compared four approaches to optimize acceptance of strawberry yogurt and 276 observed that the JAR scales were an acceptable alternative to more 277 complicated methodologies based on different deterministic and probabilistic 278 preference mapping approaches. The overall liking mean for the ideal product 279 obtained using JAR scales was not significantly different to that obtained with 280 the other methods tested. Villegas et al (2009b) used the JAR scales to assess 281 the appropriateness of specific sensory attribute levels of different formulations 282 of a new prebiotic vanilla beverage. According to the results obtained, 283 perceptible differences in color, sweetness, vanilla flavor, and thickness, due to 284 sample formulation, were detected by consumers. Moreover, the highest 285 variability was detected in the appropriateness of the level of sweetness, vanilla 286 flavor and thickness. For example, despite color differences, defined by 287 instrumental and sensory analyses, practically all samples were considered to 288 have an optimal color level by consumers. The percentage of consumers 289 considering the samples' color "just about right" was over $79 \%$ except for one of 290 the samples (68\%). Vanilla flavor appropriateness highly varied between samples. None of the samples showed a minimum of $70 \%$ of the responses in

292 the "just about right". The results revealed that variations in the composition of 293 vanilla beverage samples can produce products whose sensorial differences 294 are perceived by the consumer; however, not all these differences influenced 295 consumer response to the same extent. The Just About Right (JAR) scales can 296 be a good alternative to link the sensory differences perceived by consumers 297 with product acceptance and can reveal to what extent the sensory differences 298 consumers perceive influence acceptability. However JAR scales are not 
appropriate to study the psychophysical (stimuli-sensory response) or

300 psychohedonic (sensory response-liking) functions. Despite their practical

301 validity, the main drawbacks of JAR scales are related with the interpretation

302 and analysis of the JAR data and how these data relate to hedonics (Gacula et

303 al., 2007 and 2008, Xiong \& Meullenet, 2006).

304

305 Influence of consumer habits and attitudes on hedonic ratings and on purchase intention

307 The influence of food habits, attitudes, beliefs, and opinions on food choice and 308 purchase is of particular importance in the acceptance or rejection of foods 309 (Schifferstein, 2001; Jaeger, 2006, Villegas et al., 2009a). The most commonly

310 used methods to investigate consumers' attitudes, beliefs and opinions can be 311 classified in two main groups: qualitative and quantitative (Chambers and

312 Smith, 1991; Lawless and Heymam, 1998). The first ones, such as focus

313 groups or in-depth interviews, are of an exploratory nature. They generate oral-

314 descriptive, non-numerical information, and are usually carried out within small

315 groups of people. The second ones are usually based on questionnaires where 316 the answers to different questions are generally presented numerically.

317 However, the latter method requires responses to be gathered from much larger

318 groups of people than the qualitative methods.

320 When the research topic concerns certain personality traits or attitudes towards complex topics such as the degree of interest in health or factors influencing the acceptance of certain products, using a single simple scale does not usually

323 provide enough information. In these situations, multiple scales comprising a 
324 group of Likert scales are the most common and the interviewee uses them to

325 indicate a degree of agreement or disagreement with several statements related

326 to the topic under study. Each sub-scale measures an aspect of a common

327 factor, which constitutes the basis for the construction of multiple scales. It 328 enables a single score to be obtained for each individual by adding the values

329 procured with each sub-scale. An example of this type of scale is the one 330 designed to measure consumers' attitudes towards new food (Food Neophobia 331 Scale) by Pliner and Hobden in 1992. This scale comprises ten Likert sub332 scales of seven points to measure the degree of agreement or disagreement for 333 each of the expressions selected to represent different attitudes to new food.

334 Steptoe et al. (1995) developed and validated some multiple scales in order to 335 measure the factors influencing food choice (Food Choice Questionnaire). The 336 aforementioned questionnaire included aspects related to health and to food 337 flavour, as well as a wide range of factors related to their choice. Likewise, 338 Roininen et al. (1999) developed a questionnaire to measure the relative 339 importance that different aspects related to health and sensorial characteristics 340 have in the food selection process (Health and Taste Attitudes Questionnaires).

341 The latter questionnaire included three multiple scales related to health:

342 General health interest; Light product interest and Natural product interest and

343 three related with hedonic aspects: Craving for sweet foods; using foods as

344 reward and Pleasure. These scales can be used to determine and quantify the

345 individual attitudes of a group of consumers and to analyze how well these 346 attitudes can predict their behavior when faced with the choice of different types 347 of foods. 
349 In a recent work (Villegas et al., 2008), we studied how the habitual

350 consumption of milk and soya beverages or certain attitudes, such as an

351 interest in healthy eating (Roininen et al., 1999) or food neophobia (Pliner \&

352 Hobden, 1992) affect hedonic ratings and purchase intention with respect to

353 milk and soybean vanilla beverages. On analyzing the differences in sample

354 acceptability between consumers and non-consumers of soymilk, a significant

355 effect was found of the interaction between this consumer habit and sample

356 acceptability. Habitual soymilk consumers awarded significantly higher

357 acceptability values to this type of beverage. However, differences were not

358 detected in the acceptability of the milk samples between consumers and non-

359 consumers of soymilk. This would seem to confirm that habitual consumption of

360 a food increases its acceptability. Luckow et al. (2005) observed a significant

361 increase in the acceptability of a series of probiotic beverages after they had

362 been consumed daily for a week, and Stein et al. (2003) found a positive

363 correlation between familiarity and the level of liking in a study on the

364 acceptance of bitter beverages. Consumer population distribution in terms of

365 their interest in healthy eating and their attitudes to new foods indicated that

366 most people in the population were interested in eating healthily and that very

367 few consumers displayed neophobia. Accordingly, respondents were divided

368 into tertiles depending on their scale values, using the 33rd and 66th percentile

369 points as cut-off points. The moderate group was removed in order to study the

370 subgroups with more clearly defined attitudes. While differences in the degree

371 of consumer neophobia did not influence either acceptability or purchase

372 intention, differences in the degree of interest in eating healthily influenced both

373 acceptability and purchase intention for the different samples. A soy beverage 
374 sample was considered significantly more acceptable by consumers with higher

375 interest in eating healthily. Moreover, the aforementioned group of consumers 376 declared a significantly higher purchase intention for all soymilk samples. These

377 results are in accordance with the observations reported by Aaron et al (1994)

378 and by Tuorila et al (1998) concerning the relationship between consumer

379 attitudes and beliefs and their response to food. The former authors observed

380 that when consumers tasted the samples, the effects of information were more

381 important on purchase intention than on hedonic ratings and Tourila and co-

382 workers found that nutritional information had an effect on purchase interest but

383 less impact on the perceived pleasantness of a snack food.

385 To what extent do the expectations created by different types of 386 information affect hedonic ratings?

387 Consumers' expectations, of either sensory or hedonic characteristics, can be generated by a variety of factors and play an important role in food selection and consumption. Subsequent confirmation or disconfirmation can lead to either repeated consumption or rejection of a product. Related to food acceptance the key question is how the confirmation or disconfirmation of these expectations affects food acceptance (Cardello, 1994). Four models, based on four psychological theories, can be used to explain how disconfirmation created by expectations may influence product acceptance: Assimilation, Contrast, Generalized negativity and Assimilation-contrast (Cardello \& Sawyer, 1992;

396 Tourila et al., 1994; Deliza \& MacFie, 1996). The assimilation model predicts 397 that regardless of whether positive or negative disconfirmation occurs, any discrepancy between expected and actual liking of a product is assimilated by 
399 the consumer and the actual linking moves in the direction of the expected

400 liking. The contrast model assumes the opposite to the assimilation model and 401 predicts that actual liking moves in the opposite direction to expectation. The 402 generalized negativity model predicts that product acceptance decreases when 403 any type of disconfirmation between expected and actual acceptance occurs. 404 The assimilation-contrast model is a combination of both the assimilation and 405 the contrast models and is based on the existence of certain limits on 406 acceptance of rejection of a product by consumers. According to Cardello 407 (1994) this model predicts that assimilation will occur when the acceptance of 408 the product differs only slightly to moderately from expectations; however, when 409 the acceptance differs significantly from expectations, a contrast effect occurs. 410 Among these four models, the assimilation and the contrast models are the 411 ones that usually predict the consumer response under conditions of positive or 412 negative disconfirmation more accurately (Mialon et al., 2002; Di Monaco et al., 413 2004; Napolitano et al., 2007, Behrens et al, 2007).

415 Recently, Villegas et al (2008) studied how hedonic ratings and purchase 416 intention were affected by information type (picture of real package or card with 417 beverage type and nutritional facts) in commercial milk and soybean vanilla 418 beverages. The results show that package characteristics can influence 419 consumers' opinion about possible product acceptability and their purchase 420 intention. A badly designed or unattractive package can make consumers think 421 the product is of low quality, thereby dimishing their interest in acquiring it. By 422 contrast, a well-designed package suggests that the product it contains is high 423 quality and increases the consumer's interest in acquiring it. When the 
424 consumer, as well as seeing the package, tastes the product, the package may

425 not influence either acceptance or purchase intention. In general, consumers'

426 response to the expectations generated by the two information types followed

427 an assimilation model. However, an analysis of the individual responses

428 indicated different response trends in terms of the information type. The

429 percentage of consumers whose response fitted the assimilation model was

430 higher for the samples of soy-milk beverages (55-67\%) than for the dairy

431 beverages (31-64\%), independent of information type supplied. Globally, the

432 percentage of consumers that were not influenced by the information or whose

433 response did not follow a clear model was greater for the dairy beverages (32-

$43457 \%)$ than for the soy-milk ones (16-36\%). This leads us to the conclusion that

435 acceptance depends not only on the expectation generated by information

436 (including nutritional facts), but also on the sensory properties of a food product.

437 Similar results were obtained by Solheim \& Lawless (1996) who analyzed the

438 influence of price and fat content information and liking on consumer purchase

439 probability of regular fat and reduced fat Cheddar cheese. No difference was

440 detected between hedonic ratings given in blind tastings and those awarded

441 when information was given together with the samples. They also observed

442 that liking and sensory factors exerted greater influence on purchase choice

443 than information about fat content; leading them to the conclusion that the key

444 to repurchasing lies in how much the cheese is enjoyed when consumed.

\section{Conclusion}

447 The acceptance or rejection of a given food occurs when the human brain jointly 448 processes: a) information obtained from observing, handling and consuming the 
449 food in question; b) information acquired from the surrounding social and 450 cultural context; c) information gained from the physiological effects (pleasure, 451 satiety, dislike, discomfort, etc) experienced when eating and after eating a certain food and d) comparison with information stored in the memory of past experiences. Depending on the subject under study, different approaches and methodologies may be adopted to study food acceptability as discussed in this paper. Therefore one must take care to select the most suitable tool to assess each case and to consider both its appropriateness and its possible drawbacks.

\section{Acknowledgement}

459 To MICINN of Spain for financial support (Project AGL 2007-63444). To Fondo 460 Social Europeo for financing the contract of author S. Bayarri in the program I3P 461 from CSIC. The useful comments of the two anonymous reviewers are 462 gratefully acknowledged.

463

\section{References}

465 Aaron JI, Mela DJ \& Evans RE (1994) The Influences of Attitudes, Beliefs and 466 Label Information on Perceptions of Reduced-Fat Spread. Appetite, 22, 25-37.

467 Acosta O, Viquez F \& Cubero E (2008) Optimisation of low calorie mixed fruit 468 jelly by response surface methodology. Food Quality and Preference, 19, 79-85.

469 Barrios EX \& Costell E (2004) Review: Use of methods of research into 470 consumers' opinions and attitudes in food research. Food Science and 471 Technology International, 10, 359-371.

472 Barrios EX, Bayarri S, Carbonell I, Izquierdo L \& Costell E (2008) Consumer 473 attitudes and opinions toward functional foods: A focus group study. Journal of 474 Sensory Studies, 23, 514-525.

475 Behrens JH, Villanueva NDM \& Da Silva MAAP (2007) Effect of nutrition and 476 health claims on the acceptability of soyamilk beverages. International Journal 477 of Food Science and Technology,I 42: 50-56

478 Bruhn CM, Cotter A, Diaz-Knauf K, Sutherlin J, West E, Wightman N, 479 Williamson E \& Yaffee M. (1992). Consumer attitudes and market potential for 480 foods using fat substitutes. Journal of Dairy Science 75 (9), 2569-2577. 
Caporale G \& Monteleone E. (2001). Effect of expectations induced by 482 information on origin and its guarantee on the acceptability of a traditional food: 483 olive oil. Sciences des Aliments 21 (3), 243-254.

484 Carbonell L, Izquierdo L, Carbonell I \& Costell E (2008) Segmentation of food 485 consumers according to their correlations with sensory attributes projected on 486 preference spaces. Food Quality and Preference, 19, 71-78.

487 Cardello AV (1994) Consumer expectations and their role in food acceptance. 488 In: HJH MacFie and DMH Thomson (Eds.). Measurement of Food Preferences 489 pp 253-297. Blackie Academic and Professional, London.

490 Cardello AVA and Sawyer FM (1992) Effects of disconfirmed consumer 491 expectations on food acceptability. Journal Sensory Studies, 7, 253-277.

492 Chambers E. \& Smith EA. (1991). The uses of qualitative research in product 493 research and development. In: HT Lawless \& BP. Klein (Eds.), Sensory Science 494 Theory and Applications in Foods, pp 395-412. Blackie Academic \& 495 Professional, London,

496 Choi ID, Phillips RD \& Resurreccion AVA (2007) Consumer-based optimization 497 of a third-generation product made from peanut and rice flour. Journal of Food 498 Science, 72, S443-S449.

499 Connor R \& Douglas L (2001) Consumer attitudes to organic foods. Nutrition 500 and Food Science, 31, 254-264.

502

Costell E, Pastor MV, Izquierdo L \& Duran L (2000) Relationships between acceptability and sensory attributes of peach nectars using internal preference mapping. European Food Research and Technology, 211, 199-204.

504 Damasio $\mathrm{MH}$, Costell E \& Duran L (1999) Optimising acceptability of low-sugar 505 strawberry gels segmenting consumers by internal preference mapping. Journal 506 of the Science of Food and Agriculture, 79, 626-632.

507 de Araujo IET, Rolls ET, Kringelbach ML, McGlone F \& Phillips N (2003) Taste508 olfactory convergence, and the representation of the pleasantness of flavour, in 509 the human brain. European Journal of Neuroscience, 18, 2059-2068.

510 Deliza R \& Macfie HJH (1996) The generation of sensory expectation by 511 external cues and its effect on sensory perception and hedonic ratings: $A$ 512 review. Journal of Sensory Studies, 11, 103-128.

513 Deliza R, MacFie H \& Hedderley D (2005) The consumer sensory perception of 514 passion-fruit juice using free-choice profiling. Journal of Sensory Studies, 20, 515 17-27.

516 Delwiche J (2004) The impact of perceptual interactions on perceived flavor. 517 Food Quality and Preference, 15, 137-146. 
518 Di Monaco R, Cavella S, Di Marzo S \& Masi P (2004) The effect of expectations 519 generated by brand name on the acceptability of dried semolina pasta. Food 520 Quality and Preference, 15, 429-437.

521 Dijksterhuis, GB \& Gower JC (1991/2) The interpretation of generalized 522 procrustes analysis and allied methods. Food Quality and Preference, 3, 67-87

523 Dinehart ME, Hayes JE, Bartoshuk LM, Lanier SL, Duffy VB (2006) Bitter taste markers explain variability in vegetable sweetness, bitterness and intake. Physiology and behaviour, 87, 304-313

526 Epler S, Chambers E \& Chen XQ (1998) Hedonic scales are a better predictor than just-about-right scales of optimal sweetness in lemonade. Journal of Sensory Studies, 13, 191-197

Gacula M, Rutenbeck S, Pollack L, Resurreccion AVA, Moskowitz HR (2007) The Just-about-right intensity scale: Functional analyses and relation to hedonics. Journal of Sensory Studies, 22, 194-211

Gacula M, Mohan P, Faller J, Pollack L \& Moskowitz HR (2008) Questionnaire practice: What happens when the jar scale is placed between two "overall" acceptance scales? Journal of Sensory Studies, 23, 136-147.

Gan HE, Karim R, Muhammad SKS, Bakar JA, Hashim DM \& bd Rahman R (2007) Optimization of the basic formulation of a traditional baked cassava cake using response surface methodology. LWT-Food Science and Technology, 40, 611-618.

539 Gains N (1994) The repertory grid approach. In: HJH MacFie and DMH 540 Thomson (Eds.). Measurement of Food Preferences pp 51-75. Blackie 541 Academic and Professional, London.

542 Gains N. \& Thomson DMH. 1990. Contextual evaluation of canned lagers using 543 repertory grid method. International Journal of Food Science and Technology. 544 25, 699-705.

545 Gomez C, Fiorenza F, Izquierdo L \& Costell E (1998) Perception of mealiness 546 in apples: a comparison of consumers and trained assessors. Zeitschrift fur 547 Lebensmittel-Untersuchung Und-Forschung A-Food Research and Technology, 548 207, 304-310.

549 Gonzalez-Tomas L \& Costell E (2006) Sensory evaluation of vanilla-dairy 550 desserts by repertory grid method and free choice profile. Journal of Sensory 551 Studies, 21, 20-33.

552 Gower JC (1975) Generalized procrustes analysis. Psychometrika, 40 (1), 3355351

554 Greenhoff K \& MacFie HJH (1994) Preference mapping in practice. In: HJH 555 MacFie and DMH Thomson (Eds.). Measurement of Food Preferences pp 137556 166. Blackie Academic and Professional, London. 
557 Guerrero L, Colomer Y, Guardia MD, Xicola J. \& Clotet R. (2000) Consumer

558 attitude towards store brands. Food Quality and Preference 11 (5), 387-395.

559 Harker FR, Gunson FA \& Jaeger SR (2003) The case for fruit quality: an 560 interpretive review of consumer attitudes, and preferences for apples. 561 Postharvest Biology and Technology, 28, 333-347.

562 Hashim IB, Resurreccion AVA \& McWatters KH. (1996) Consumer attitudes 563 toward irradiated poultry. Food Technology 50 (3), 77-80.

564 Heldman DR (2004). Identifying food science and technology research needs. 565 Food Technology, 58: 32-34.

566 Hersleth M, Mevik BH, Naes T \& Guinard JX (2003) Effect of contextual factors 567 on liking for wine-use of robust design methodology. Food Quality and 568 Preference, 14, 615-622.

569 Jaeger SR (2006) Non-sensory factors in sensory science research. Food 570 Quality and Preference, 17, 132-144.

571 Jaeger SR, Rossiter KL \& Lau K (2005) Consumer perceptions of novel fruit 572 and familiar fruit: a repertory grid application. Journal of the Science of Food 573 and Agriculture, 85, 480-488.

574 Jaeger SR, Rossiter KL, Wismer WV \& Harker FR (2003) Consumer-driven 575 product development in the kiwifruit industry. Food Quality and Preference, 14, 576 187-198.

577 Jahan K, Paterson A \& Piggott JR (2005) Sensory quality in retailed organic, 578 free range and corn-fed chicken breast. Food Research International, 38, 495579503

580 Lawless HT \& Heymam H (1998). Sensory Evaluation of Food. Principles and 581 Practices. Chapman \& Hall, New York,

582 Lovely C \& Meullenet JF (2009) Comparison of preference mapping techniques 583 for the optimization of strawberry yogurt. Journal of Sensory Studies, DOI: 584 10.1111/j. 1745-459X2009.00221.x

585 Luckow T, Sheehan V, Delahunty C \& Fitzgerald G (2005) Determining the odor and flavor characteristics of probiotic, health-promoting ingredients and the effects of repeated exposure on consumer acceptance. Journal of Food Science, 70, S53-S59.

589 Lundgren B, Jonsson B, Pangborn RM, Sontag AM, Barylko-Pikielna N, 590 Pietrzak E, Dos Santos Garruti R, Chaib Moraes, MA, Yoshida M (1978) Taste 591 discrimination vs. hedonic response to sucrose. An interlaboratory study, 592 Chemical Senses, 3, 249-265

593 Magnusson MK \& Koivisto $H$, (2002). Consumer attitudes towards genetically 594 modified foods. Appetite 39 (1), 9-24. 
Meilgaard M, Civille GV \& Carr BT (1999) Sensory evaluation techniques. CRC

596 Press. Boca Raton, Fla, USA.

597 Meullenet JF, Xiong R, Findlay, CJ (2007) Multivariate and probabilistic 598 analyses of sensory science problems. IFT Press, Blackwell, Ames, lowa, USA.

599 Mialon VS, Clark MR, Leppard PI \& Cox DN (2002) The effect of dietary fibre 600 information on consumer responses to breads and "English" muffins: a cross601 cultural study. Food Quality and Preference, 13, 1-12.

602 Moskowitz HR (1996) Experts versus consumers: A comparison. Journal of 603 Sensory Studies, 11, 19-37.

604 Napolitano F, Caporale G, Carlucci A \& Monteleone E (2007) Effect of 605 information about animal welfare and product nutritional properties on 606 acceptability of meat from Podolian cattle. Food Quality and Preference, 18, 607 305-312.

608 Oreskovich DC, Klein BP \& Sutherland JW (1991) Procrustes analysis and its 609 application to free choice and other sensory profiling. In: Lawless and Klein 610 (eds.) Sensory Science Theory and Application in Foods, pp. 353-394. Marcel 611 Dekker, New York, USA.

612 Pastor MV, Costell E, Izquierdo L \& Duran L (1996) Optimizing acceptability of a 613 high fruit low sugar peach nectar using aspartame and guar gum. Journal of 614 Food Science, 61, 852-855.

615 Pearson D (2002) Marketing organic food: Who buys it and what do they 616 purchase? Food Australia, 54, 31-34.

617 Piggott JR, Sheen MR \& Apostolidou SG (1990) Consumers' perceptions of 618 whiskies and other alcoholic beverages. Food Quality and Preference, 2, 177619185.

620 Pliner P \& Hobden K (1992) Development of A Scale to Measure the Trait of 621 Food Neophobia in Humans. Appetite, 19, 105-120.

622 Prescott J (2004) Psycological processes in flavour perception. In: Taylor and 623 Roberts (eds.) Flavor Perception, pp 256-27. Blackwell Publ. Ltd, Oxford, UK.

624 Resurreccion AVA \& Galvez FCF (1999) Will consumers buy irradiated beef? 625 Food Technology 53 (3), 52-55.

626 Rodbotten M, Martinsen BK, Borge GI, Mortvedt HS, Knutsen SH, Lea P \& 627 Naes T (2009) A cross-cultural study of preference for apple juice with different 628 sugar and acid contents. Food Quality and Preference, 20, 277-284.

629 Roininen K \& Tuorila H (1999) Health and taste attitudes in the prediction of use 630 frequency and choice between less healthy and more healthy snacks. Food 631 Quality and Preference, 10, 357-365. 
632 Roininen K, Lahteenmaki L \& Tuorila H (1999) Quantification of consumer

633 attitudes to health and hedonic characteristics of foods. Appetite, 33, 71-88.

634 Rolls E (2005). Taste, olfactory and food texture processing in the brain, and the

635 control of food intake. Physiol. Behavior. 85: 45-56

636 Russell CG \& Cox DN (2003) A computerised adaptation of the repertory grid 637 methodology as a useful tool to elicit older consumers' perceptions of foods.

638 Food Quality and Preference, 14, 681-691.

639 Santa Cruz MJ, Martinez MC \& Hough G (2002) Descriptive analysis, consumer 640 clusters and preference mapping of commercial mayonnaise in Argentina. 641 Journal of Sensory Studies, 17, 309-325.

642 Schifferstein H (2001) Effects of product beliefs on product perception and liking 643 In: Frewer, Risvik \& Schifferstein (eds.) Food, People and Society. A European 644 Perspective of Consumers' Food Choices, pp 73-96. Springer Verlag, Munich, 645 Germany.

646 Shepherd R (1989) Factors influencing food preferences and choice. In: 647 Shepherd (ed.), Handbook of the Psychophysiology of Human Eating. pp. 3-24.

648 John Wiley and Sons Ltd, Chichester, UK.

649 Shepherd, R \& Sparks, P. (1994). Modelling food choice. In: H. J. H. MacFie \& 650 D. M. Thomson (Eds.). Measurement of Food Preferences, pp 202-223. Blackie

651 Academic \& Professional, London,

652 Siró I, Kàpolna E, Kàpolna B, Lugasi A (2008). Functional food. Product 653 development, marketing and consumer acceptance. A review. Appetite: 51, $654 \quad 456-457$

Small DM \& Prescott J (2005). Odor / taste integration and the perception of 656 flavour. Exp. Brain Res. 166: 345-357

658

Solheim R \& Lawless HT (1996) Consumer purchase probability affected by 659 attitude towards low-fat foods, liking, private body consciousness andinformation on fat and price. Food Quality and Preference, 7, 137-143

660 Stein LJ, Nagai H, Nakagawa M \& Beauchamp GK (2003) Effects of repeated exposure and health-related information on hedonic evaluation and acceptance of a bitter beverage. Appetite, 40, 119-129.

663 Steptoe A, Pollard TM. \& Wardle J (1995). Development of a measure of the 664 motives underlying the selection of food: the Food Choice Questionnaire. 665 Appetite 25 (3), 267-284.

666 Sundqvist NC, Stevenson RJ \& Bishop IRJ(2006). Can odours acquire fat-like 667 properties? Appetite 47: 91-99

668 Tenenhaus M, Pages J, Ambroisine L \& Guinot C (2005) PLS methodology to 669 study relationships between hedonic judgements and product characteristics. 670 Food Quality and Preference, 16, 315-325. 
671 Thybo AK, Kuhn BF \& Martens H (2004) Explaining Danish Childrens

672 preferences for apples using instrumental, sensory and

673 demographic/behavioural data. Food Quality and Preference, 15, 53-63

674 Tuorila H, Andersson A, Martikainen A \& Salovaara H (1998) Effect of product

675 formula, information and consumer characteristics on the acceptance of a new

676 snack food. Food Quality and Preference, 9, 313-320.

677 Tuorila H, Cardello AV \& Lesher LL (1994) Antecedents and Consequences of

678 Expectations Related to Fat-Free and Regular-Fat Foods. Appetite, 23, 247-

679263.

680 Urala N \& Lahteenmaki L (2004) Attitudes behind consumers' willingness to use

681 functional foods. Food Quality and Preference, 15, 793-803.

682 Verbeke W, Sioen I, Pieniak Z, Van Camp J \& De Henauw S (2005) Consumer

683 perception versus scientific evidence about health benefits and safety risks from

684 fish consumption. Public Health Nutrition, 8, 422-429.

685 Vigneau E \& Qannari EM (2002) Segmentation of consumers taking account 686 external data. A clustering of variables approach. Food Quality and 687 Preference,13, 515-521

688 Villegas B, Carbonell I \& Costell E (2008) Effects of product information and 689 consumer attitudes on responses to milk and soybean vanilla beverages.

690 Journal of the Science of Food and Agriculture, 88, 2426-2434.

691 Villegas B, Carbonell I \& Costell E. (2009a) Acceptability of Milk and Soymilk

692 Vanilla Beverages. Demographics Consumption Frequency and Sensory

693 Aspects. Food Science and Technology International, 15, 203-210

694 Villegas B, Tárrega A, Carbonell I \& Costell E. (2009b). Optimising acceptability 695 of new prebiotic low-fat milk beverages. Food Quality and Preference, DOI: 696 10.1016/j. foodqual.2009.03.001

697 von Alvensleben R (2001) Beliefs associated with food production methods. In: 698 Frewer, Risvik \& Schifferstein (eds.) Food, People and Society. A European 699 Perspective of Consumers' Food Choices, pp 381-399. Springer Verlag, 700 Munich, Germany.

701 White TL \& Prescott J (2007) Chemosensory cross-modal stroop effects: 702 Congruent odors facilitate taste identification. Chemical Senses, 32, 337-341

703 Wilcock A, Pun M, Khanona J \& Aung M (2004) Consumer attitudes, knowledge 704 and behaviour: a review of food safety issues. Trends in Food Science \& 705 Technology, 15, 56-66.

706 Xiong R \& Meullenet JF (2006) A PLS dummy variable approach to assess the 707 impact of jar attributes on liking. Food Quality and Preference,17, 188-198 
708 Zandstra EH, de Graaf C \& Van Staveren WA (2001) Influence of health and 709 taste attitudes on consumption of low- and high-fat foods. Food Quality and 710 Preference, 12, 75-82.

711 